RESEARCH PAPER RP1303

Part of Journal of Research of the National Bureau of Standards, Volume 24, June 1940

\title{
EQUIPMENT FOR CONDITIONING MATERIALS AT CONSTANT HUMIDITIES AND AT ELEVATED TEM- PERATURES
}

\author{
By James G. Wiegerink ${ }^{1}$
}

\begin{abstract}
Equipment is described for the study of the moisture relations of materials in air of controlled relative humidities at elevated temperatures. The air is brought to the desired relative humidity and temperature by an arrangement including a saturator and automatically controlled heaters, and then passed through a working chamber in which the materials to be studied can be weighed rapidly and accurately. Provision is made for measuring the rate of flow of air and for accurately determining the relative humidity in the working chamber.

The equipment has been used at temperatures from $96^{\circ}$ to $300^{\circ} \mathrm{F}$, at relative humidities from 10 to 90 percent for temperatures up to $212^{\circ} \mathrm{F}$, and up to the maximum relative humidities obtainable at atmospheric pressure for temperatures between $212^{\circ}$ and $300^{\circ} \mathrm{F}$. The temperature in the working chamber can be maintained constant within $\pm 0.4^{\circ} \mathrm{F}$ and the relative humidity within \pm 1 -percent relative humidity for experimental runs of several days' duration.

Data are given illustrating the performance of the equipment.
\end{abstract}

\section{CONTENTS}

I. Introduction

II. Description of equipment

1. General_._.

2. Saturator

3. Working chamber... 642

4. Sampling unit

III. Constancy of relative humidity and temperature

\section{INTRODUCTION}

The first step in an investigation of the drying of textiles, cooperatively undertaken by the National Bureau of Standards and the United States Institute for Textile Research, was to design and build equipment in which samples could be dried under known conditions of atmospheric humidity, temperature, and airflow. Since the equipment was planned for a study of eight or more different kinds of textiles, it was decided to provide sufficient capacity to condition 18 samples simultaneously under each drying condition. It was necessary for the equipment to be large enough to accommodate various sizes of samples and to provide a relatively large ratio of volume of chamber to volume of samples in order to insure uniform treatment of each sample. It was particularly desirable to be able to weigh the samples rapidly and conveniently while they were in the

1 Research Associate at the National Bureau of Standards, representing the United States Institnte for Textile Research. The establishment of this research associateship was made possible by funds contributed by 57 individual manufacturers. 
apparatus. Temperatures up to $300^{\circ} \mathrm{F}$ and the relative humidities corresponding to a water-vapor pressure equal to 90 percent of normal atmospheric pressure can be maintained in the conditioning chamber.

The construction and operation of the equipment are described in this paper. The equipment has been in use for 2 years and has been found to be very satisfactory.

\section{DESCRIPTION OF EQUIPMENT}

\section{GENERAL}

The four principal parts of the equipment are shown in figure 1 . Air enters the apparatus at $A$, is heated to a predetermined tempera-

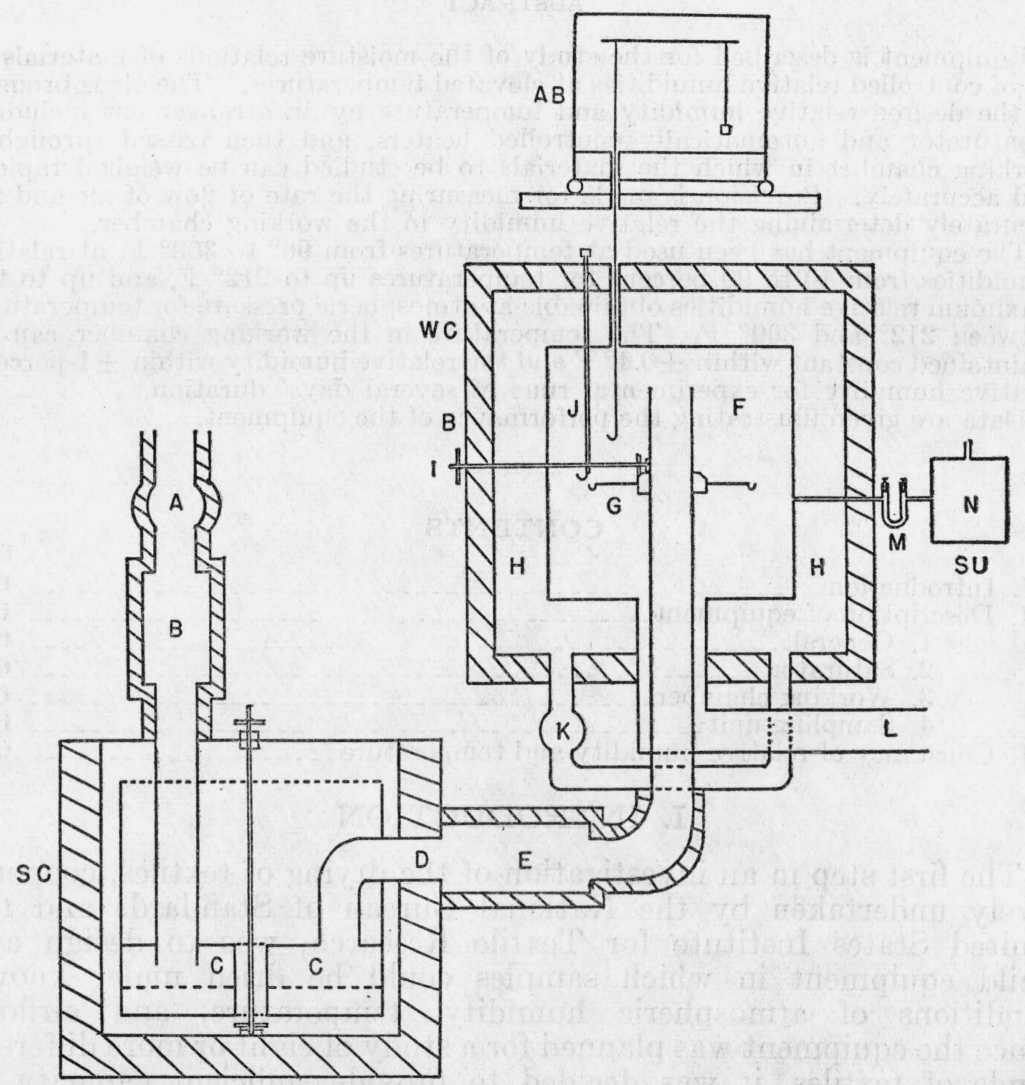

FIGURE 1.-Diagrammatic sketch of equipment for conditioning materials at constant humidities and at elevated temperatures.

$S C$, saturation chamber; $W C$, working chamber; $A B$, analytical balance; $S U$, sampling unit.

A. Air propeller.

C. First preheater. equipped with series of baffles for directing air through definite path.

D. Air outlet from conditioner.

$\boldsymbol{E}$. Second preheater.

$\boldsymbol{F}$. Working chamber.

G. Sample support (there are 18 of these arranged H. Air chamber.

I. Drive for rotating sample supports.

$j$. Mechanism for transferring sample from support to balance hook.

$K$. Air circulator.

$L$. Air outlet from working chamber.

$M$. Drying tube.

N. Wet test meter. radially). 
ture in the pipe heater, $B$, and enters a saturating chamber, $S C$, where it passes over the surface of water maintained at this temperature by a surrounding oil bath. This air, after prolonged recirculation, becomes saturated to a constant degree with water vapor at this temperature and is delivered to the working chamber, $W C$, maintained at some higher temperature. The textile samples exposed to this air in $W C$ are weighed from time to time while approaching equilibrium, using the analy tical balance, $A B$. SU is a sampling unit for gravimetrically determining the relative humidity in $W C$. Provision is made for the adjustment and automatic control of temperatures in $S C$ and $W C$, and for insulating the duct, $E$, between these two chambers to prevent condensation of moisture. The relation between the vapor pressure of water in the bath, $S C$, to that of water at the temperature of $W C$ approximately determines the relative humidity of the air in this chamber, modified to some extent by the rate at which air flows through $S C$. The exact humidity maintained in $W C$ depends upon the temperature control of both $S C$ and $W C$, together with the air flow.

\section{SATURATOR}

The air intake, $A$, is through the blower shown at the top center of figure 2. The rate of airflow through the equipment is kept constant by a blower driven by a $220-\mathrm{v}$, a-c, $1 / 20$-hp, synchronous motor. The airflow may be changed by adjustment of the dampers in the inlet and outlet sides of the blower. For most of the experimental runs, a constant airflow of about $2 \frac{1}{2} \mathrm{ft}^{3} / \mathrm{min}$ was used. At this rate, the air in the working chamber changes about every minute, which removes the water practically as fast as it is given off by the samples.

The large section, $B$, of the insulated vertical pipe for preheating the air is shown in figure 2. This brass pipe is 3 in. in diameter at the inlet and 6 in. in diameter where the heaters are located. The pipe contains two electric heaters, each with a maximum capacity of $330 \mathrm{w}$. The temperature of the air leaving this preheater is regulated to approximate the temperature of the oil bath. This condition is checked by comparing the thermocouple in the preheater with the thermocouple in the oil bath. The air then passes downward into the chamber, $C$, which is set in the oil bath.

The oil bath shown in figure 2, 22 in. in diameter and $20 \mathrm{in}$. high, is cylindrical, made of heavy-gage tinned copper, and is insulated with 4 inches of fiberboard. The outside covering of the oil bath is made of heavy-gage sheet iron. This bath is heated by means of two 500-w immersion heaters. One of these is connected with an automatic control system consisting of a mercury thermoregulator and relay. The other auxiliary heater is for quickly heating the bath to a desired temperature. The oil is circulated in the bath by a motor-driven propeller in such a manner that the oil is pulled down into the center of the bath and pushed over the side walls of the submerged water chamber. The control of the oil temperature is within $\pm 0.1^{\circ} \mathrm{F}$.

An annular water chamber, 16 in. in outside diameter and 5 in. high, which is made of heavy-gage tinned copper, is set in the oil bath. This chamber, with a water layer 3 in. deep, contains a series of baffles so constructed that the air takes a spiral path as it travels over the water surface. A reservoir of 1-gallon capacity, and a 
constant-leveling device set in the bath maintain the water supply. The 1-gallon oilcan mounted on the bath is for filling the reservoir, which is below it, without interfering with the operation of the leveling mechanism.

The air passes from the saturating equipment at $D$ and then through the horizontal insulated pipe, $E$, shown under the working chamber in figure 3. This pipe contains two electric heaters, each with a maximum capacity of $500 \mathrm{w}$, and one electric heater with a maximum capacity of $1,000 \mathrm{w}$. This last heating unit is seldom used except for quickly raising the temperature to that desired. The air is heated in this preheater to the temperature at which it is to be used and passes upward to the interior of the working chamber.

\section{WORKING CHAMBER}

The inside of the working chamber, $W C$, is shown in figure 4 . The cylindrical inner chamber, about 18-in. in diameter and 18-in. high, is made of heavy-gage copper and provided with a door containing a window. The samples under test hang from Nichrome rings at the ends of 18 horizontal rods, $G$, which are arranged radially about the air-inlet pipe and revolve around it four times a minute. The motor for rotating the sample supports may be seen on the top left-hand side of the working chamber in figure 3 .

Air of the desired temperature and relative humidity enters the inner chamber, $F$, at the top through the central vertical standpipe, passes downward over the samples, $G$, and out through a passage around the intake pipe, $L$. Recirculation is provided by a connection between $L$ and $A$.

The inner chamber is surrounded by an air jacket, $H$, as shown in figure 4. This air jacket is surrounded by $1 / 4-i n$. of Transite and 2-in. of fiberboard, the exterior surface being made of heavy-gage sheet iron. The working chamber is rectangular, 26 by 26 by 26 -in. inside dimensions. It is supported by the angle-iron base shown in figure 3 .

The air jacket is heated by three sets of electric plug-in heaters placed respectively at the bottom, center, and top (fig. 4). The bottom and center heaters each consist of two $660-\mathrm{w}$ plug-in units connected in series to consume a maximum of $330 \mathrm{w}$. The top heaters, with a maximum of $330 \mathrm{w}$, are connected with the automatic control system, consisting of a mercury thermoregulator and relay. During an experimental run, sufficient heat is applied to the air jacket by the bottom and center heaters to bring the temperature within a few degrees of the temperature desired, the remaining amount of heat being supplied by the automatic control system. The air in this jacket, $H$, is circulated by withdrawing it from one side by means of the blower, $K$, shown at the bottom in figure 3 , and then blowing it into the other side. The air returns over a partition which separates the two sides and extends to within a few inches of the top of the air jacket.

The temperature of the working chamber can be controlled within $\pm 0.4^{\circ} \mathrm{F}$ for the range $96^{\circ}$ to $300^{\circ} \mathrm{F}$. Thermocouples are placed at the top and bottom of the working chamber to indicate any changes of temperature. The temperature of the air is recorded continuously during a test by a resistance-type recording thermometer, not shown. 


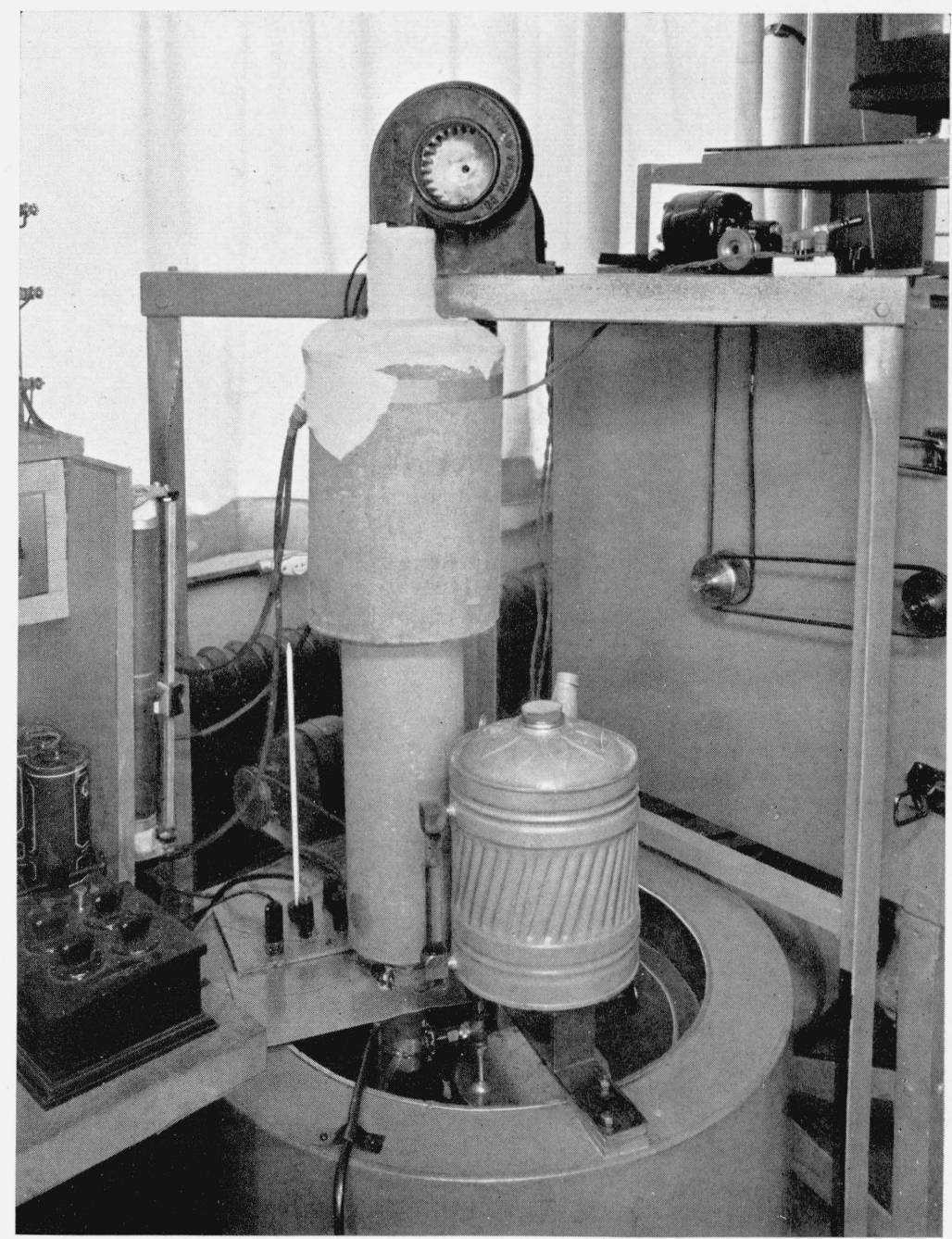

Figure 2.-Air-säturating equipment. 


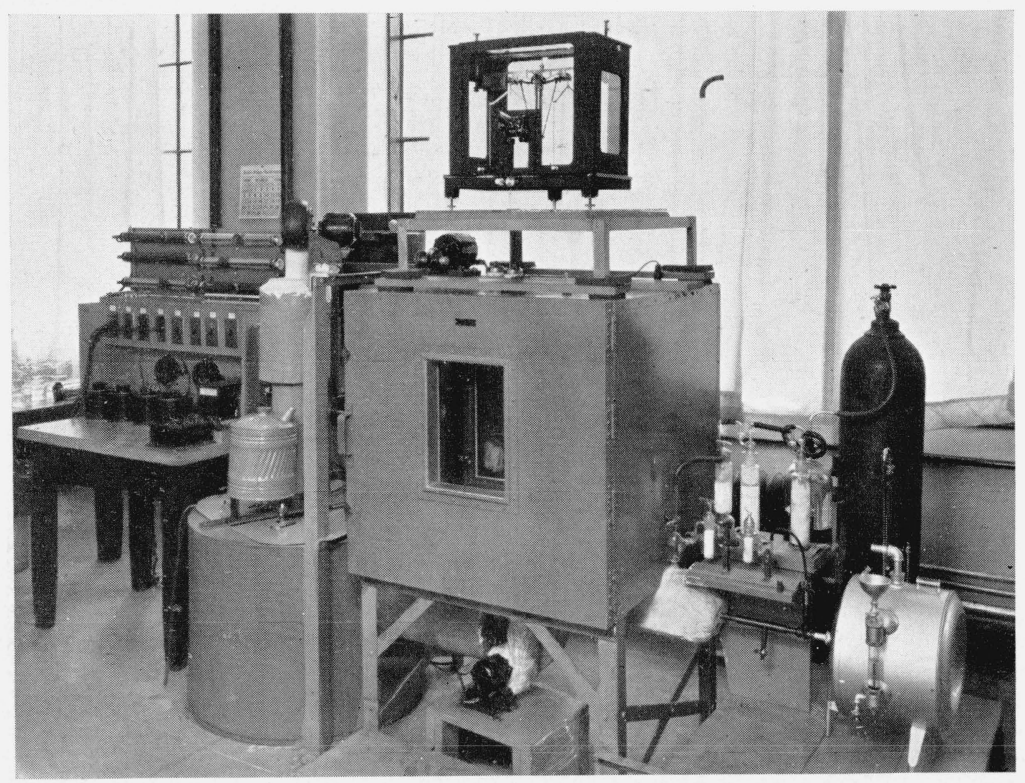

Figure 3.-General view of the equipment. 


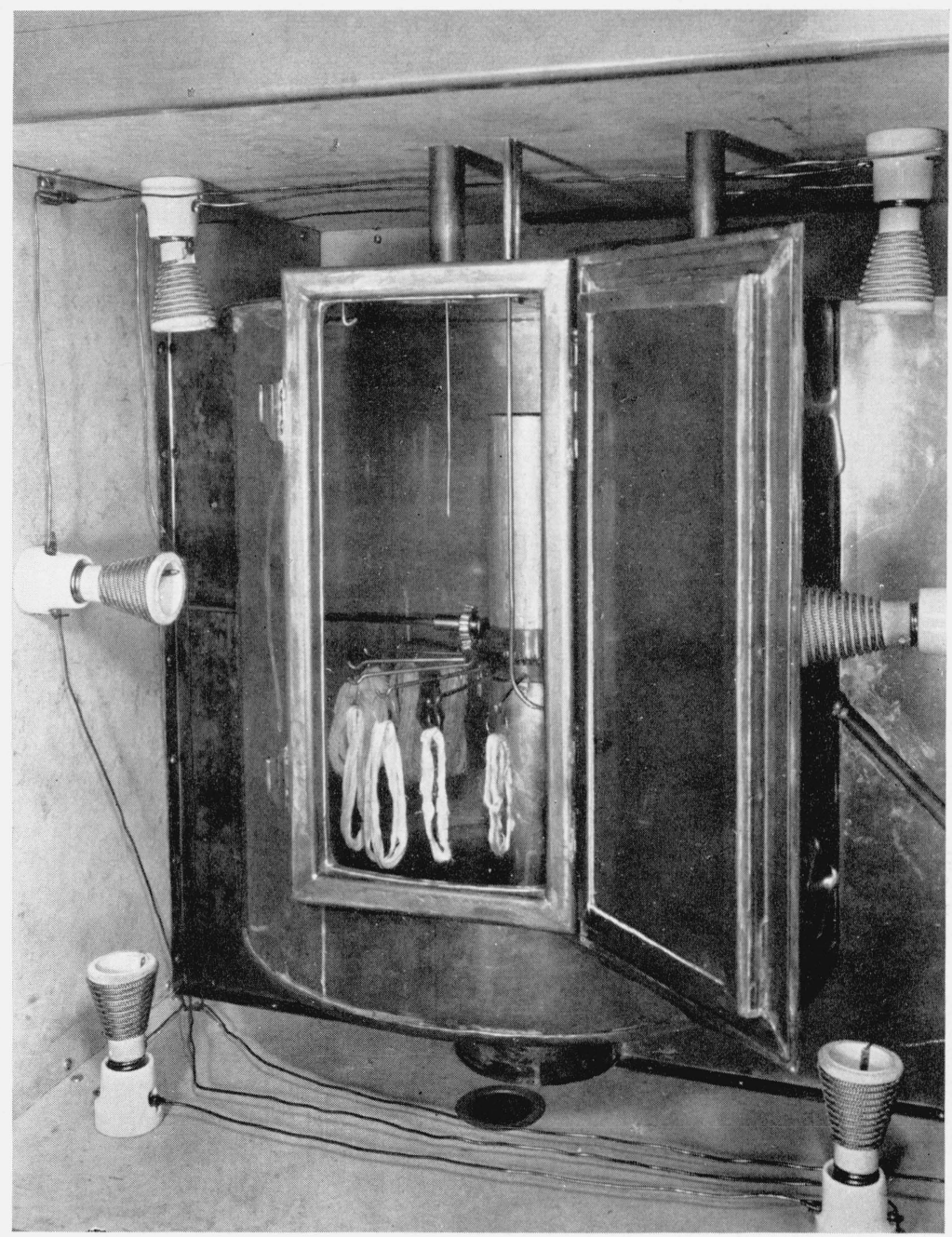

Figure 4.-Inside of working chamber. 
Windows in the inner and outer chambers make it possible to see the samples when transferring them by means of $J$ from the supports to a Nichrome wire which extends into the working chamber from the bottom of the balance pan. This wire passes downward from the balance through a heated glass cylinder, through which dry air is passed, and through an iris diaphragm. When a weighing is to be made, the rotation of the samples is stopped, the sample is transferred to the rod, and weighed. This takes only 10 to 15 seconds with the magnetically damped balance provided. With the above arrangement, no difficulty was experienced from the rise of warm air about the wire or from the condensation of moisture on it.

The air from the inner chamber passes out through $L$, to which a wet test meter may be attached when flow measurements are desired. However, if the air is not recirculated, relative humidities above 65 percent at temperatures up to $212^{\circ} \mathrm{F}$ are not practicable. By recirculating the air from the outlet, $L$, of the working chamber to the blower, $A$, it is possible to obtain approximately a relative humidity of 90 percent at $212^{\circ} \mathrm{F}$ with an airflow of $2 \frac{1}{2} \mathrm{ft}^{3} / \mathrm{min}$. It was necessary to provide proper insulation and a heater for this return duct in order to reduce condensation of moisture to a minimum. This return duct is not shown in any of the figures. It is located behind the working chamber.

On the table at the left in figure 3 are the switchboard and the electric control equipment. Four variable transformers for regulating some of the heating circuits are also mounted on the table. To the right of the transformers are a galvanometer and a standard resistance box for reading thermocouples. Above the transformers are two relays which are in the automatic temperature-control circuits. Above the switches are slide-wire resistors for the manual regulation of some of the heaters and motors.

\section{SAMPLING UNIT}

The relative humidity in the working chamber may be determined gravimetrically by means of a sampling unit, $S U$, shown to the right of the working chamber in figure 3. Air containing moisture is withdrawn from the working chamber, the moisture being adsorbed by the $\mathrm{Mg}\left(\mathrm{ClO}_{4}\right)_{2} \cdot 3 \mathrm{H}_{2} \mathrm{O}$ in the drying tubes. The amount of moisture is determined, and the relative humidity is calculated from a knowledge of the temperature in the working chamber, the weight of the moisture, and the volume and temperature of the air analyzed. The volume of air is measured by means of a wet-test meter, $N$, of $1 / 4-\mathrm{ft}^{3}$ capacity per revolution, with an accuracy of 0.5 percent. The temperature of the air varies from $70^{\circ}$ to $80^{\circ} \mathrm{F}$ (room temperature). This gravimetric method gives the relative humidity to within \pm 0.5 -percent relative humidity.

It was found necessary to provide a means of driving over into the drying tubes any moisture that may condense between the equipment and the drying tubes, particularly at the higher temperatures and higher relative humidities. This was done by placing a glass trap between the equipment and the drying tubes. After a run is made, this condensed water was then driven into the $\mathrm{Mg}\left(\mathrm{ClO}_{4}\right)_{2} \cdot 3 \mathrm{H}_{2} \mathrm{O}$ with dry air. The dry air is produced by taking compressed air from a tank and passing it over sulfuric acid, $\mathrm{Mg}\left(\mathrm{ClO}_{4}\right)_{2} \cdot 3 \mathrm{H}_{2} \mathrm{O}$ and $\mathrm{P}_{2} \mathrm{O}_{5}$. 


\section{CONSTANCY OF RELATIVE HUMIDITY AND TEMPERATURE}

The constancy of the relative humidity in the working chamber under operating conditions may be judged from table 1 . These results are typical of the experiments that have been made with the equipment while in operation for the past 2 years.

TABLE 1.-Constancy of relative humidity

\begin{tabular}{|c|c|c|c|}
\hline Time & $\begin{array}{l}\text { Relative humi- } \\
\text { dities at } 96^{\circ} \mathrm{F}, \\
\text { with recircula- } \\
\text { tion }\end{array}$ & Time & $\begin{array}{l}\text { Relative humi- } \\
\text { dities at } 96^{\circ} \mathrm{F} \text {, } \\
\text { without re- } \\
\text { circulation }\end{array}$ \\
\hline $\begin{array}{l}\text { Beginning } \\
\text { End of } 24 \mathrm{hr} \\
\text { End of } 48 \mathrm{hr} \\
\text { End of } 72 \mathrm{hr} \\
\text { End of } 96 \mathrm{hr}\end{array}$ & $\begin{array}{r}\text { Percent } \\
92.3 \\
92.3 \\
92.1 \\
92.5 \\
92.3\end{array}$ & $\begin{array}{l}\text { Beginning } \\
\text { End of } 12 \mathrm{hr} \\
\text { End of } 24 \mathrm{hr} \\
\text { End of } 36 \mathrm{hr} \\
\text { End of } 60 \mathrm{hr}\end{array}$ & $\begin{array}{r}\text { Percent } \\
62.9 \\
63.3 \\
63.0 \\
63.2 \\
63.1\end{array}$ \\
\hline Average..- & 92.3 & Average_..... & 63.1 \\
\hline Time & $\begin{array}{l}\text { Relative humi- } \\
\text { dities at } 219^{\circ} \mathrm{F}, \\
\text { with recircula- } \\
\text { tion }\end{array}$ & Time & $\begin{array}{l}\text { Relative humi- } \\
\text { dities at } 219 \mathrm{~F} \text {, } \\
\text { without re- } \\
\text { circulation }\end{array}$ \\
\hline $\begin{array}{l}\text { Beginning } \\
\text { End of } 4 \mathrm{hr} \\
\text { End of } 8 \mathrm{hr} \\
\text { End of } 24 \mathrm{hr}\end{array}$ & $\begin{array}{r}\text { Percent } \\
79.2 \\
79.0 \\
79.4 \\
79.0\end{array}$ & \multirow{2}{*}{$\begin{array}{l}\text { Beginning } \\
\text { End of } 4 \mathrm{hr} \\
\text { End of } 8 \mathrm{hr} \\
\text { End of } 24 \mathrm{hr} \\
\text { Average }\end{array}$} & $\begin{array}{r}\text { Percent } \\
15.8 \\
16.2 \\
16.0 \\
16.4\end{array}$ \\
\hline Average & 79. 2 & & 16.1 \\
\hline
\end{tabular}

Acknowledgment is made to A. C. Walker, chairman, and Frederic Bonnet, member, Administration Committee for Drying Research, United States Institute for Textile Research, and to W. D. Appel, of the National Bureau of Standards, for valuable suggestions in the development of the constant-humidity and constant-temperature equipment.

Washington, March 14, 1940. 